\title{
UMA ANÁLISE ENUNCIATIVO-DISCURSIVA DOS "PERCURSOS INTERNOS DE LEITURA" ENCENADOS NA PRODUÇÃO TEXTUAL DE PRÉ-UNIVERSITÁRIOS
}

\author{
Luiz André Neves de Brito* \\ Universidade Federal de São Carlos \\ São Carlos, São Paulo, Brasil
}

\begin{abstract}
Resumo: $O$ artigo tem como objetivo apresentar resultados parciais de uma análise discursivo-enunciativa de um corpus representativo de redações da FUVEST/2007, produzidas por candidatos selecionados em primeira chamada do vestibular. Assumindo a vertente da Análise do Discurso ligada à perspectiva da enunciação, focalizo as condições imediatas de produção para analisar (i) os pontos de heterogeneidade mostrada a partir da relação coletânea/textos produzidos; e (ii) o acontecimento "cristalizado" desse percurso interno de leitura. Por meio dessa análise, defendo que (i) o gênero discursivo seja uma das instâncias que regula o modo como o discurso outro será mostrado; e (ii) a leitura mostrada pelo escrevente, no contexto de vestibular, é atravessada por préconstruídos que circulam em uma dada sociedade.
\end{abstract}

Palavras-chave: Análise do discurso. Escrita de pré-universitários. Percursos internos de leitura.

\section{INTRODUÇÃO}

Neste trabalho, apresento resultados parciais da pesquisa que tenho desenvolvido com textos produzidos por alunos egressos do ensino médio. A situação de produção desses textos é o exame para ingresso na universidade. Para este artigo, o material analisado corresponde a um

\footnotetext{
* Professor Adjunto I, UFSCar. Doutor em Filologia e Língua Portuguesa pela Universidade de São Paulo. Email: luizandrenevesdebrito@gmail.com
} 
conjunto de 346 redações produzidas no vestibular da FUVEST/2007 que foram selecionadas aleatoriamente e cedidas pela FUVEST. Vale salientar que esse conjunto corresponde a cerca de $1 \%$ das redações produzidas no ano de 2007 e compreende apenas as redações dos candidatos aprovados em primeira chamada.

Filiando-me à vertente da Análise do Discurso ligada à perspectiva da enunciação, centro a análise no modo como as condições imediatas engendram a produção escrita do escrevente pré-universitário, ou seja, o foco da análise é investigar o modo como o escrevente se apropria dos textos da coletânea apresentados na prova de redação da FUVEST/2007 ${ }^{1}$ para produzir seu texto. Para falar sobre o acontecimento dessa atividade de leitura, divido a análise em dois momentos: (i) no primeiro momento, mostro as formas marcadas e não marcadas de apropriação dos textos da coletânea; (ii) no segundo momento, abordo o porquê de certos fragmentos da coletânea serem mais susceptíveis à destacabilidade para, em seguida, mostrar como esses modos de representação do discurso outro são atravessados por leituras cristalizadas (estereotipadas), fazendo circular o imaginário social que inspira e alimenta um determinado grupo e sua época.

\section{DANDO INÍCIO À DISCUSSÃO...}

A redação de vestibular tem se mostrado um objeto de estudo instigante para os estudiosos da linguagem que se preocupam em refletir sobre os desafios que a escrita propõe. Tomando como base a classificação proposta por Tfouni (2010) sobre os estudos do letramento, compreendo as pesquisas sobre a escrita de pré-universitários a partir de duas perspectivas: (1) uma a-histórica, que se caracteriza pelo estudo da escrita como "crise" da linguagem; (2) outra histórica, que se caracteriza pelo estudo da escrita numa perspectiva discursiva.

Seguindo as reflexões de Tfouni (2010), a perspectiva a-histórica caracteriza-se por seu posicionamento individualista-restritivo, tecnológico e cognitivista. Por ser individualista-restritiva, leva em consideração a

\footnotetext{
${ }^{1}$ A prova de redação realizada no ano de 2007 encontra-se no anexo.
} 
aquisição da escrita enquanto código, isto é, o que está em jogo é o aprendizado de habilidades específicas dessa atividade; por ser tecnológica, apresenta "uma visão positiva dos usos da leitura/escrita, relacionando-os com o progresso da civilização e o desenvolvimento tecnológico" (TFOUNI, 2010, p. 51); por ser cognitivista, enfatiza o aprendizado como produto das atividades mentais, partindo do pressuposto de que o conhecimento e as habilidades têm origem no próprio indivíduo e de que este é o responsável central pelo processo de aquisição da escrita.

Buscando enfatizar as habilidades e os conhecimentos do indivíduo, a perspectiva a-histórica compreende a escrita como uma espécie de produto completo em si mesmo. O agravante dessa perspectiva é o fato de considerar letrados somente os indivíduos que sabem ler e escrever "bem", gerando estudos comparativos entre grupos que fazem uso "inadequado" e os que fazem uso "adequado" da linguagem. O mais agravante ainda é que estes últimos acabam sendo tomados como a norma, o esperado, o desejado.

Nessa perspectiva, concebe-se a linguagem como uma mera atividade de adequação, ou seja, a linguagem como uma atividade ligada à eficácia da comunicação. Voltando-se para o produto escrito (o texto fechado sobre si mesmo), o foco desses estudos é discutir a crise na linguagem (isto é, as falhas de textualidade, os problemas da escrita) e, como consequência, avaliar a produção textual segundo parâmetros dicotômicos, tais como: formal e informal; correto e incorreto; textos eficazes com bom padrão de textualidade e textos deficientes com problemas de textualidade. Em suma, esses estudos observam a atividade escrita como um espaço discursivo logicamente estabilizado em que o sujeito se inscreve de modo adequado ou não, o que o leva a produzir textos eficazes ou deficientes. Portanto, ao associar a escrita à noção de adequação, esses estudos chegam comumente à conclusão de que a atividade escrita está em crise e, consequentemente, deficiente.

Na contramão desses estudos, interessa-me acentuar que a escrita não é apenas uma mera atividade de adequação às regras de uso da língua e à situação de comunicação. Ou seja, procurando não cair no risco de reproduzir um discurso catastrofista, tenho conduzido a pesquisa por uma 
vereda diferente dos estudos que dão ênfase à crise na linguagem. Na trilha das reflexões de Corrêa, fugir desse discurso catastrofista é fugir de um discurso que se quer denunciatório. Diz o autor:

No campo da educação, essa função de denúncia tem direções bem determinadas, ora dirigindo-se ao aluno, ora ao professor. No entanto, esse mesmo discurso ganha um aspecto duplo, ao mesmo tempo denunciatório e denunciativo. Ou seja, apresenta críticas bem conhecidas sobre a produção textual (é denunciatório), mas, no modo de fazê-lo, denuncia em si mesmo a separação entre educação e cultura (é denunciativo dos pressupostos que o orientam), reservando para a primeira o papel da educação formal e restringindo a segunda à chamada alta cultura. (CORRÊA, 2006, p. 142).

Ademais, a investigação que desenvolvo, embora considerando a dimensão textual, distancia-se do tratamento do texto como categoria sobre a qual devesse incidir a tradicional visão normativa comumente aplicada a outras dimensões da linguagem.

$\mathrm{Na}$ trilha da perspectiva histórica de letramento, adotando o critério discursivo de que inter e intradiscurso não podem ser concebidos separadamente, busco compreender a redação de vestibular a partir do seguinte posicionamento: se, no intradiscurso, o sujeito escrevente, como se tivesse penetrando conscientemente no processo de enunciação ("eu sei o que escrevo"), tece o fio discursivo conduzindo o corretor à ilusão de um texto linear, coeso e coerente, que apresenta "introdução", "desenvolvimento" e "conclusão", no interdiscurso, por ser uma dispersão de vozes (ou melhor, uma dispersão de leituras), esse mesmo sujeito lida com a ilusão de não ser a origem do seu dizer. Nesse sentindo, entendo a escrita não como a tradução literal do pensamento.

Perseguindo esse princípio discursivo, compreendo a redação de vestibular não como um mero produto final do processo de textualização, mas, como um processo sócio-histórico, um acontecimento a ler e a escrever. Nesse sentido, a questão central é abordar a linguagem como processo e não como produto; é pensar a linguagem na sua dimensão dialógica intimamente ligada a fatos sócio-históricos, ou seja, é preciso abordar a ocorrência da linguagem sob seu caráter histórico - que se 
manifesta a partir dos vínculos estabelecidos entre a atualidade do acontecimento e a retomada de um já-dito - e dialógico - que se manifesta não só da interação de interlocutores, mas também da emergência (de modo explícito ou implícito) na linearidade do fio discursivo de vozes pertencentes a outros discursos. No curso dessas considerações, três aspectos balizam minhas reflexões:

a) $\mathrm{O}$ fato de que conceber a linguagem na sua interioridade linguística está condenado ao fracasso quando não se estabelece "a relação entre as propriedades do discurso, as propriedades daquele que o pronuncia e as propriedades da instituição que o autoriza a pronunciá-lo" (BOURDIEU, 1998, p. 89). Nesse sentido, a análise de uma prática discursiva deve se encontrar na juntura da linguagem e da instituição que produz e faz circular os enunciados (cf. MAINGUENEAU, 2005);

b) A concepção de que o sujeito escrevente é um efeito do caráter intersubjetivo-dialógico da linguagem, isto é, o sujeito é um efeito da sua constante negociação com a heterogeneidade do seu discurso. Nesse sentido, compreende-se que o lugar do outro no discurso não é ao lado do sujeito escrevente, mas constitutivo do seu próprio discurso (cf. AUTHIER-REVUZ, 2004);

c) Por fim, a compreensão de que a linguagem, mais do que uma questão de adequação (um meio para se chegar a certos fins), é uma questão de acontecimento - o ponto de encontro de uma atualidade e uma memória (a retomada de um já-experimentado, um já-dito/escrito e um já-ouvido/lido) (cf. PÊCHEUX, 2002).

Em suma, a pesquisa segue uma vereda diferente dos estudos que dão ênfase à "crise da linguagem" e, procurando não cair no risco de reproduzir um discurso catastrofista, concebe a redação no vestibular para além das questões estritamente linguístico-textuais. Em outras palavras, compreendo a redação não como um texto enquanto texto (mero artefato linguístico), mas, como um dispositivo enunciativo sócio-historicamente condicionado. 


\section{CONTEXTUALIZANDO A PESQUISA}

Movida pelo pressuposto de que tanto leitura quanto escrita são práticas sociais que, em relação, integram cada momento do nosso cotidiano, a pesquisa que tenho desenvolvido busca investigar o acontecimento discursivo da relação leitura/escrita em textos de préuniversitários. Mais precisamente, a minha questão volta-se para o modo como a prática de leitura gera ressonâncias dialógicas na prática escrita. Perseguindo essa dialogia da escrita com o já-lido, busco mostrar o modo como o escrevente, ao produzir seu texto, encena percursos de leitura, atando-os e produzindo efeitos de sentido.

A investigação que proponho é conduzida pela hipótese de que o estatuto leitor do escrevente, no interdiscurso, é constituído por uma dispersão de leituras, enquanto, no intradiscurso, o estatuto inscritor do escrevente é chamado a dar "nó" a essa dispersão. Para perseguir essa hipótese, o referencial teórico-metodológico da pesquisa centra-se: (i) em torno de uma questão maior da linguagem, a dimensão dialógica da palavra, levando em consideração fatos discursivos registrados no texto que fazem explodir a transparência da linguagem e a unidade do sujeito escrevente; e (ii) nos estudos enunciativos, principalmente, nos estudos desenvolvidos por Authier-Revuz, cuja perspectiva abre espaço para as relações intersubjetivas, a abordagem da linguagem como espaço da constituição da subjetividade e o questionamento da unicidade enunciativa.

Tendo em vista esse referencial teórico-metodológico, um dos objetivos da pesquisa é mostrar o modo como o escrevente préuniversitário encena a leitura da coletânea de textos apresentada pela prova de redação. Esse processo de referência aos textos da coletânea corresponde ao que chamo de percurso interno de leitura (mais à frente, explico melhor esse percurso de leitura). Para a investigação desse processo, adoto como categoria de análise tanto as formas explícitas/marcadas (por exemplo, citações diretas e indiretas, modalização em discurso segundo etc.) como também as formas interpretativas/não marcadas (por exemplo, as citações escondidas, alusões, reminiscências) de representação do discurso outro (AUTHIER-REVUZ, 1998). 


\section{ACONTECIMENTO DA LEITURA NA ESCRITA DE PRÉ-UNIVERSITÁRIOS}

A redação de vestibular mostra-se um gênero discursivo instigante para o estudo da relação leitura/escrita, pois, conforme sabemos, a prova de redação é marcada tanto por um exercício de leitura quanto por um exercício de produção textual. Nesse sentido, vejo a redação de vestibular caracterizada como um texto extremamente marcado pela atividade de leitura, mostrando-se, portanto, como um material interessante não só para análise dos percursos de leitura encenados pelo escrevente préuniversitário, como também para observação do modo como a esfera escolar pauta a prática de leitura desse escrevente.

Para abordar essa questão da leitura nos interstícios da escrita de préuniversitários, retomo a pesquisa desenvolvida por Duarte (1998), que, sob o enfoque metodológico do paradigma indiciário, investigou procedimentos de leitura na realização da prova de redação do Vestibular UNICAMP. Ao explicar esses procedimentos de leitura, a autora busca reconstruir o caminho percorrido pelos candidatos com o intuito de entender melhor os motivos que fizeram com que os candidatos escrevessem o que escreveram e da forma como escreveram.

Segundo Duarte, a redação é um texto extremamente marcado pela atividade de leitura, logo um material interessante para análise de procedimentos de leitura, pois traz nos seus interstícios marcas de intertextualidade reveladoras desses procedimentos. Apesar de as condições de produção serem aparentemente "iguais" para todos os candidatos, os tipos de procedimentos de leitura encontrados levaram a autora a defender a hipótese de que os textos produzidos não se constituíram por condições de produção homogêneas, mas condições diversificadas associadas à história de constituição de cada sujeito (caso contrário todas as redações seriam iguais). A partir dos indícios levantados, a autora extrai as seguintes generalizações:

Há candidatos que, [...], articulam criativamente, segundo um projeto de escrita, as informações da coletânea. Há candidatos que, [...], condicionados, por vezes, por certas ideologias, produzem sentidos um tanto estranhos, especialmente se confrontados com o sentido dos 
textos da coletânea. Há candidatos que, [...], pressupõem o conhecimento da coletânea e escrevem uma redação como se estivessem resolvendo uma tarefa escolar. Há candidatos que, [...], trazem um texto "pronto" de casa, o qual muito provavelmente já tenha sido discutido em sala de aula. (DUARTE, 1998, p. 143).

Fundamentando-se em uma concepção de leitura como uma atividade discursiva e como um processo de construção de sentido a partir de estratégias de percepção dos sememas, Duarte, tendo em vista os conceitos de polifonia e intertextualidade, busca marcas de intertextualidade explícita para mostrar os procedimentos de leitura descritos acima. Com base nos resultados obtidos, a autora constata que os diferentes tipos de procedimentos de leitura são consequência da própria história de constituição desses candidatos como sujeitos de linguagem e de seus projetos de dizer (que, segundo a pesquisadora, são constituídos dentro dos processos escolares). A autora, portanto, percebe que o projeto de dizer orienta, nessa situação específica, também a maneira como os candidatos leem. Além disso, os quatro tipos de procedimentos revelam indícios do que venha a ser uma redação de Vestibular (ou seja, do modo como esse "gênero" é entendido nas escolas, por alunos e professores) e de todo um processo histórico-social caracterizador dos sujeitos autores.

Filiando-me à pesquisa de Duarte, busco ressaltar como a redação no evento vestibular propicia uma situação interessante para mostrar a atividade de leitura não como uma atividade meramente subjetiva, mas como uma atividade discursiva. Ou seja, nessa perspectiva, não se pode aceitar leituras individuais (cada um lendo como queira), mas sim que há comunidades discursivas que leem como leem porque têm a história que têm. Assim como Duarte, acredito que "toda leitura se faz em função de um projeto do leitor, motivado pelo seu projeto de escrita" (DUARTE, 1998, p. 148). Mas, acredito também que todo projeto de escrita é motivado por um projeto de leitura. Dito isso, compreendo a relação leitura/escrita como eixo organizador do gênero redação no vestibular. 


\section{O ACONTECIMENTO DA LEITURA ENTRE INTERTEXTUALIDADES INTERNAS E EXTERNAS}

Para abordar a relação leitura/escrita, filio-me às considerações de Maingueneau sobre intertextualidade. Para Maingueneau (2005), enquanto o intertexto corresponde ao conjunto de fragmentos que o discurso cita efetivamente, a intertextualidade corresponde aos tipos de relações intertextuais que a competência discursiva define como legítimos. Essa intertextualidade é, então, evocada sob dupla modalidade: interna (isto é, memória discursiva interior ao campo) e externa (isto é, memória discursiva exterior definida em sua relação com outros campos).

Pensando nessa dupla modalidade da intertextualidade, defendo a ideia de que todo o processo de escrita no evento vestibular se dá na constante relação entre percursos internos e externos de leitura. Enquanto o percurso interno de leitura é engendrado pela memória discursiva interna ao evento marcada pelo acontecimento da leitura dos textos da coletânea, o percurso externo de leitura é engendrado por uma memória discursiva externa ao evento marcada pelo acontecimento da leitura de textos alémcoletânea (discurso outros que atravessam a leitura do tema).

Perseguindo as reflexões de Maingueneau, compreendo, portanto, como a intertextualidade desenha implicitamente um modo de coexistência dos textos na produção textual das redações, ou seja, a intertextualidade delimita uma espécie de "biblioteca constituinte" fiadora dos fragmentos que podem/devem ser citados efetivamente. Dito isso, o intertexto que emerge nos interstícios das redações diz obliquamente quais "fragmentos de textos" são legitimados pela instituição.

No caso das redações, é possível observar como esse intertexto está associado a um corpo de enunciadores consagrados (autorizados) e como engendra, sobretudo, a modalidade interna da intertextualidade. Podemos, então, remeter essa questão aos critérios de constituição de uma massa documental pertinente para uma posição enunciativa determinada, pois, ao tecer sua rede intertextual, o discurso constrói em um mesmo movimento o grafo de seu espaço documental. É nesse movimento que a "biblioteca constituinte" inscrita nos interstícios das redações faz circular, direta ou 
indiretamente, citações "célebres" de autores literários e de pensadores consagrados (e de suas obras), citações proverbiais, citações de máximas etc. Além de funcionar como fator de qualificação do escrevente, delimitando que "saber" é necessário possuir para enunciar legitimamente, o intertexto (isto é, o conjunto "citável" dessa biblioteca) valida a imagem de leitor que o escrevente é chamado a nela inscrever. Em outras palavras, quero dizer (e mostrar) que a legitimação discursiva do projeto de dizer do escrevente supõe uma certa "competência leitora".

O escopo deste trabalho recai sobre os percursos internos de leitura engendrados pelas condições imediatas de produção. Proponho-me a investigar os modos de inscrição da atividade de leitura envolvida na relação entre coletânea/instrução e os textos produzidos. Mais precisamente, proponho-me a analisar os vários modos como o escrevente faz circular os textos da coletânea.

Partindo do princípio dialógico de que nós falamos com as palavras dos outros para construirmos nossos discursos, ressalto que a unidade de análise desta pesquisa corresponde ao espaço discursivo que emerge de um sistema de remissões ao discurso outro. Esse processo de remissão à palavra do outro deve ser visto, a meu ver, da seguinte forma: (a) como um processo metalinguístico do modo como o escrevente interpreta o discurso outro; (b) o modo ativo como o escrevente recepciona/legitima/autoriza/faz circular o discurso outro; (c) o modo responsivo como o discurso outro é emoldurado pela entonação expressiva do escrevente que o relata. Ademais, vale ressaltar que o discurso outro existe para o escrevente em dois aspectos: "como palavra alheia dos outros, cheia de ecos de outros enunciados" e "como a minha palavra, porque, uma vez que eu opero com ela em uma situação determinada, com uma intenção discursiva determinada, ela já está compenetrada da minha expressão" (BAKHTIN, 2003, p. 294).

\section{MODOS DE REFERÊNCIA AO DISCURSO OUTRO}

Apresento, neste ponto, a tipologia assumida como base de análise, filiando-me: (i) às observações de Authier-Revuz (1998; 2004) sobre 
modos de representação do discurso outro; (ii) aos trabalhos de Maingueneau (2006) sobre os usos das citações; (iii) aos estudos desenvolvidos sobre modos de apropriação do discurso outro na escrita acadêmica no Laboratoire de linguistique et didactique des langues étrangères et maternelles (LIDILEM) da Universidade Stendhal, Grenoble III (BOCH; GROSSMANN, 2002; RINCK; BOCH; GROSSMANN, 2006); (iv) às reflexões de Corrêa (2004) sobre a escrita de préuniversitários, em que são abordados os modos como o escrevente toma a coletânea como "ponto de heterogeneidade mostrada".

Assumindo essas filiações, busco um duplo desafio: (i) interrogarme, portanto, sobre o modo como o discurso outro é inscrito (se inscreve) no fio discursivo, dedicando-me à descrição das formas da heterogeneidade mostrada, que devem ser entendidas como modos de negociação do sujeito com a heterogeneidade constitutiva; e (ii) reafirmar a hipótese defendida por Corrêa (2001; 2004), que concebe a heterogeneidade como constitutiva da escrita e não exterior a ela, ou seja, uma concepção que assume a heterogeneidade não como presente na escrita, mas como própria da escrita. Retomando as palavras de Authier-Revuz (2004, p. 69), todo discurso se mostra constitutivamente atravessado pelos "outros discursos" e pelo "discurso do Outro", sendo o outro entendido não como objeto exterior do qual se fala, mas uma condição do discurso de um sujeito falante que não é fonte-primeira do discurso.

A tipologia que proponho para analisar os percursos internos de leitura parte da seguinte distinção em três níveis proposta por AuthierRevuz (1998): (a) formas marcadas unívocas; (b) formas marcadas que exigem um trabalho interpretativo; (c) formas puramente interpretativas.

Apropriando-se dessa distinção, as formas marcadas (a) e (b) correspondem aos modos explícitos de representação de um discurso outro, por exemplo: a remissão aos textos da coletânea por citações diretas e indiretas ou por modalizações em discurso segundo e a colagem aspeada de fragmentos da coletânea (ilhotas citacionais). Com base nos estudos de Boch e Grossmann (2002), agrupo as remissões por citações indiretas e as modalizações em discurso segundo sob a denominação de reformulação. 
Portanto, enquanto "a citação [direta] cria um espaço autônomo no plano enunciativo, a reformulação permite ao escritor integrar a fala do outro em seu próprio dizer, assumindo-a do ponto de vista enunciativo" (BOCH; GROSSMANN, 2002, p. 100)

Já as formas interpretativas (c) correspondem a modos não-marcados de representação do discurso outro que diluem as fronteiras do outro no mesmo, isto é, o outro é integrado à cadeia discursiva sem ruptura sintática, por exemplo: os casos de alusões aos textos da coletânea por meio de itens lexicais ou de remissões aos textos da coletânea por meio de citações escondidas.

Com base nos estudos de Maingueneau sobre o uso das citações, vejo que tanto a alusão quanto a citação escondida podem ser agrupadas sob a noção de particitação. Segundo o autor (2006), a particitação difere da citação prototípica por ser um sistema de citação em que o locutor cita sem indicar a fonte ou nem mesmo deixa marcas de que efetuou uma citação (por exemplo, o não uso de aspas ou de verbos dicendi). Além disso, no sistema de particitação, "o locutor que cita pressupõe pragmaticamente que ele mesmo e seu alocutário são membros da mesma comunidade", isto é, "o locutor cita aquilo que poderia/deveria ser dito pelo alocutário e, mais amplamente, por qualquer membro da comunidade que age de maneira plenamente conforme a esse pertencimento" (MAINGUENEAU, 2006, p. 92). Dito isso, pode-se compreender a particitação como uma forma particular de coenunciação, pois, segundo o autor, haveria um acordo entre os interlocutores em torno de um ponto de vista atribuído à figura de um hiperenunciador que legitima/valida/autoriza o dito.

Em suma, serão analisados os seguintes modos de referência aos textos da coletânea. Ver quadro 1:

\section{Quadro 1: Modos de referências aos textos da coletânea}

\begin{tabular}{|l|l|}
\hline Formas marcadas & Formas não-marcadas \\
\hline 1. Remissões por citação direta; & 3. Particitação: \\
2. Reformulações & 3.1 alusão aos textos da coletânea; \\
2.1 por citações indiretas; & 3.2 citações escondidas dos textos da \\
2.2 por modalização em discurso segundo. & coletânea. \\
\hline
\end{tabular}




\section{OS PERCURSOS INTERNOS DE LEITURA: ENTRE FORMAS MARCADAS E NÃO MARCADAS}

As formas marcadas de heterogeneidade mostrada representam as forças centrípetas da heterogeneidade constitutiva, construindo uma proteção necessária para que um discurso seja mantido, assegurando a identidade do "eu", dando corpo ao discurso (pelos contornos, limites que traçam) e forma ao sujeito enunciador (pela atividade metalinguística que encenam). Em outras palavras, "é ao corpo do discurso e à identidade do sujeito que remetem as diversas formas da heterogeneidade mostrada em sua relação com a heterogeneidade constitutiva" (AUTHIER-REVUZ, 1990 , p. 34). Para a autora, as formas marcadas correspondem a modos explícitos de representação do discurso outro. Neste trabalho, essas formas correspondem à remissão aos textos da coletânea por citação direta, às reformulações por citação indireta ou discurso segundo e às ilhotas textuais.

No caso da remissão aos textos da coletânea por citação direta, "são as próprias palavras do outro que ocupam o tempo - ou o espaço claramente recortado da citação na frase; o locutor se apresenta como simples porta-voz" (AUTHIER-REVUZ, 2004, p.12). Vejamos alguns dados extraídos do corpus:

\section{Exemplo 1}

A amizade é considerada, desde tempos remotos, como um dos maiores tesouros do homem. A seu respeito, Cícero, pensador da Antigüidade Clássica, teria afirmado: "os deuses imortais nada nos deram de melhor, nem de mais agradável”. (Texto $31,1^{\circ} \S$ );

\section{Exemplo 2}

Como tudo o que é precioso, no entanto, a amizade verdadeira é difícil de ser encontrada. O pensador Montaigne chegou a escrever que "se encontramos facilmente homens aptos a travar conosco relações superficiais, o mesmo não acontece quando procuramos uma intimidade sem reservas". Esse escrito data do século XVI, e no entanto ainda pode ser considerado extremamente válido nos dias de hoje. (Texto $31,2^{\circ} \S$ ). 
Linguisticamente falando, pode-se ver que, nos enunciados acima, o escrevente relata as falas aspeadas como realmente proferidas por Montaigne e Cícero; o escrevente dramatiza um efeito de autenticidade. Esse é o efeito de sentido que a remissão por citação direta constrói pelo fato de supostamente indicar as "próprias palavras" do enunciador citado. Outro elemento característico do discurso direto é o uso de verbos introdutores. Nos enunciados acima, podemos observar o uso de verbos dicendi (teria afirmado) e uso de verbos scribendi (chegou a escrever).

Tanto em (1) quanto em (2), vê-se que o escrevente mostra um enunciador (que é outra pessoa) asseverando um certo posicionamento, isto é, o escrevente introduz em seu discurso uma voz que não é a sua, mas que é responsável pelo posicionamento que atribui a si. Tudo isso pode ser traduzido nas seguintes palavras de Ducrot:

Neste caso, X (que é, ao mesmo tempo falante e locutor) faz ouvir, numa enunciação que reivindica como sua, a voz de $\mathrm{Y}$ asseverando que ele sabe tudo. Exprimirei esse fato dizendo que o enunciado, embora dado a $\mathrm{X}$ como autor da enunciação (=locutor), atribui, no entanto, a Y (=enunciador da asserção de onisciência) uma asserção que $\mathrm{X}$ não assume como sua, mas que, contudo é dada como efetuada na própria enunciação pela qual $\mathrm{X}$ é responsável. (DUCROT, 1987, p.141).

Dando continuidade à reflexão, a citação direta é, comumente, tida como de funcionamento "fiel" e "objetivo" no plano semânticoenunciativo, porém, conforme se pode observar nos exemplos acima, o discurso direto não pode ser nem objetivo nem fiel, uma vez que a situação de enunciação dos textos de Cícero e de Montaigne é reconstruída pelo escrevente que a relata. Portanto, ao citar um determinado fragmento e não outro, o escrevente dá a ele um enfoque pessoal, revestindo-o de entonações expressivas argumentativas. Trata-se de uma citação direta em que o escrevente delimita entre aspas o ponto de vista que ele busca apreender para validar o seu posicionamento.

Em (1), por exemplo, a citação direta emerge para validar a formulação (A amizade é considerada, desde tempos remotos, como um dos maiores tesouros do homem) que a antecede, ou seja, a formulação prepara 
o terreno argumentativo para emersão da citação que ajuda a reforçar o posicionamento do escrevente.

Nos dois exemplos acima, nota-se que, por intermédio da reformulação por citação direta, o escrevente não só valida o seu posicionamento como explicita sua adesão aos posicionamentos de Cícero e de Montaigne. Ademais, em nenhum momento pode-se dizer que a reformulação por citação direta não sofre influência por parte do escrevente; pelo contrário, tanto a escolha do fragmento quanto a posição que ele ocupa no texto (antecedendo ou sucedendo o posicionamento defendido pelo escrevente) mostram a presença de um sujeito trabalhando a linguagem. Em outras palavras, quero dizer que a individualidade do escrevente citante não é jamais apagada: as aspas que delimitam o fragmento a ser citado resultam, também, de um trabalho interpretante do escrevente.

Dando continuidade às formas marcadas de heterogeneidade mostrada, vejamos os dados a seguir:

\section{Exemplo 3}

Nota-se, através do tempo, uma constante alteração na concepção de amizade. Cícero, pensador da Antiguidade, concebe a amizade como um sentimento estritamente de amparo e companheirismo. Já Montaigne, quinze séculos mais tarde, crê numa visão mais escassa de amizade, era que tal sentimento é tão difícil de se encontrar que trocaria um reino para obte-lo. (Texto $14,2^{\circ} \S$ );

\section{Exemplo 4}

Como Cícero sabiamente menciona, a emoção é inócuo se não compartilhada, e um amigo lhe permitirá explorar os melhores emoções da vida até sua plenitude energética (Texto 05, $4^{\circ} \S$ ).

Nos exemplos (3) e (4), verificam-se dois processos de reformulação dos textos da coletânea mostrados, respectivamente, por meio da citação indireta e da modalização em discurso segundo. Na trilha das reflexões de Authier-Revuz e Maingueneau, evito reforçar a prática pedagógica de que a citação indireta é uma citação direta subordinada e assumo a citação indireta não como uma variante morfossintática derivável da citação direta, mas como um funcionamento de modo diferente da citação direta. 
Conforme podemos observar nos exemplos acima, tanto por intermédio da citação indireta quanto da modalização em discurso segundo, o escrevente citante traduz as falas citadas, isto é, o escrevente relata um outro ato de enunciação usando suas próprias palavras. Como se vê, não são as palavras exatas que são relatadas, mas sim o conteúdo do pensamento. Portanto, pode-se dizer que, diferentemente da citação direta que mostra uma cadeia significante, enunciam um conteúdo. Ou seja, ao enunciarem um conteúdo, tanto a citação indireta quanto a modalização em discurso segundo correspondem a uma operação de "reformulaçãotradução", diferentes da citação direta que corresponde a uma operação de "citação-exposição". No exemplo a seguir vejamos o que acontece:

\section{Exemplo 5}

É claro que, como bem afirmou o pensador do século XVI, Montaigne, não é nada fácil conquistar-se uma relação de "intimidade sem reservas". (Texto $06,3^{\circ} \S$ ).

O exemplo (5) é um caso típico de modalização em discurso segundo, porém no ato de reformulação há um elemento do texto de Montaigne que resiste à atividade de tradução (intimidades sem reservas) e, ao ser inserido no fio discursivo, é mostrado entre aspas. Nas palavras de Authier-Revuz (2004), o enunciado do tipo (5) não apresenta nenhum fator de ruptura, pois, o fragmento "intimidades sem reservas" (chamado de ilhota textual) é integrado e homogêneo, sintática e enunciativamente, no contexto da modalização em discurso segundo. Além disso, observo que, nessas produções textuais, as ilhotas textuais correspondem, em sua maioria, a fragmentos cristalizados da coletânea. Neste caso, por exemplo, dentre os vários fragmentos do texto de Montaigne, este é um fragmento que não pode ser dito de outro modo; que recusa qualquer processo de tradução.

Nos textos analisados, dentre os gestos de leitura da coletânea em seu modo marcado, observou-se que a reformulação por citação indireta ou por modalização em discurso segundo é mais comum do que a remissão por citação direta. O que dizer dessa observação? 
Do ponto de vista discursivo, percebe-se um cuidado do escrevente em seguir as normas do contrato genérico que considera aspectos negativos a cópia de trechos da coletânea ou o simples ato de paráfrase. Nesse sentido, pode-se dizer que o escrevente, ao evitar a remissão por citação direta, crê estar evitando a simples reprodução de trechos da coletânea. Dito isso, pode-se concluir que o escrevente faz circular uma prática pedagógica que se pauta sobre a ideia de que o "discurso direto" não passa de uma reprodução "fiel" do discurso citado. Ademais, o objetivo do escrevente é mostrar ao corretor sua habilidade de "leitor crítico", ou seja, ele busca mostrar sua capacidade interpretativa dos textos da coletânea, e uma reprodução "fiel” desses textos está longe de mostrar essa capacidade. Já a reformulação por citação indireta ou por modalização em discurso segundo é vista pelo escrevente como uma atividade de "leitura interpretativa" em que ele deixa penetrar sua voz na voz do outro. O escrevente tem a ilusão de que está falando com as próprias palavras.

Com relação às formas não marcadas (interpretativas) da heterogeneidade mostrada, pode-se dizer que tais formas são mais arriscadas por jogarem com a diluição do outro no um; em outras palavras, as formas não marcadas constituem as forças centrífugas que diluem as fronteiras do outro no mesmo. Nesse sentido, o que está em jogo no campo da enunciação é a relação entre as condições reais de existência de um discurso e da representação que dele se dá. Eis os enunciados abaixo em que o escrevente textualiza trechos de "Canção da América" (um dos textos da coletânea):

Exemplo 6

Também vale regar as sementes não tão próximas, para que virem as mais belas plantas da floresta que é nosso coração. Amizade pura é fundamental ontem, hoje e sempre para o lado esquerdo do peito. (Texto $68, \S 4^{\circ}$ ).

\section{Exemplo 7}

Enfim, sem a amizade nada seríamos e não existe nada mais belo que aquela famosa frase: "suportaria, sem dor, que todos os meus amores tivessem partidos, porém, morreria se fossem embora todos os meus amigos" para nos convencermos de que não há valor no mundo que pague uma amizade guardada debaixo de sete chaves, dentro do coração! (Texto $123, \S 6^{\circ}$ ). 
Tomando as reflexões de Maingueneau (2006; 2011) sobre o discurso relatado, poderíamos dizer que as duas formulações acima correspondem a exemplo de particitação - palavra-valise que funde "participação" e "citação". Essa noção difere da citação prototípica por não marcar em nenhum momento o discurso outro. Retomando as palavras de Authier-Revuz, a particitação pode ser compreendida como um caso em que o outro é integrado à cadeia discursiva sem ruptura sintática. Nos dois exemplos acima, vê-se que o escrevente, em nenhum dos dois exemplos, não faz uso de marcas tipológicas (as aspas), nem explicita a fonte. Esse fenômeno é uma forma particular de coenunciação, pois:

- Ao recorrer à particitação, o escrevente não diz com precisão que se trata de uma citação, nem quem é o autor citado. O escrevente conta com o conhecimento prévio do corretor. Essa citação deve ser reconhecida como um trecho de "Canção da América" pelo corretor, sem que o escrevente diga explicitamente que está citando. Isto é, cabe ao corretor perceber que há aí uma citação escondida ou alusão à "Canção da América";

- Ao enunciar "para o lado esquerdo do peito" ou "uma amizade guardada debaixo de sete chaves, dentro do coração", o escrevente põe o corretor na posição de um membro da mesma comunidade discursiva que partilha dos mesmos saberes e das mesmas condições imediatas de produção.

Como se vê, o reconhecimento de uma particitação depende ao mesmo tempo de fatores linguísticos e extralinguísticos. Os exemplos destacados nas formulações (6) e (7) correspondem a particitações em contato direto com as condições imediatas de produção.

\section{ENUNCIADOS DESTACÁVEIS E LEITURAS CRISTALIZADAS}

Pautando-nos nas reflexões de Maingueneau, podemos observar, no interior dessa prática discursiva, que certos enunciados da coletânea foram mais destacados que outros. Esses casos de destacamento, regidos pela lógica da citação de fragmentos cujo texto-fonte está logo ao lado, são 
chamados de "destacamentos fracos". Vejamos, então, como certos fragmentos dos textos da coletânea mostram-se destacáveis.

\section{EXCERTO DE CÍCERO}

Em primeiro lugar (...) [e1] pode-se realmente "viver a vida" sem conhecer a felicidade de encontrar num amigo os mesmos sentimentos? [e2] Que haverá de mais doce que poder falar a alguém como falarias a ti mesmo? [e3] De que nos valeria a felicidade se não tivéssemos quem com ela se alegrasse tanto quanto nós próprios? [e4] Bem difícil te seria suportar adversidades sem um companheiro que as sofresse mais ainda. (...) [e5] Os que suprimem a amizade da vida parecem-me privar o mundo do sol: [e6] os deuses imortais nada nos deram de melhor, nem de mais agradável.

Conforme podemos observar, o excerto de Cícero apresenta-se constituído por seis enunciados [e] destacáveis. Vejam que os três primeiros enunciados são fragmentos fortemente candidatos à destextualização por sua enunciação interrogativa, curta e generalizante. Ademais, esses enunciados mostram fortes argumentos nos quais o escrevente pode se apoiar para expor seu ponto de vista sobre a amizade. Os três últimos enunciados mostram-se como totalidades que enunciam verdades sobre a "amizade". Ao enunciar as "verdades" desses enunciados, o escrevente busca a adesão do corretor, citando o que poderia/deveria ser dito pelo corretor. Além disso, o escrevente mostra-se como um membro da comunidade pré-universitária que age plenamente de acordo com o seu pertencimento. Afirmamos isso porque encontramos no corpus vários indícios em que o escrevente textualiza os enunciados destacados acima. Eis alguns exemplos:

Exemplo 8

Porém, não se deve esquecer que nem todos são interesseiros e que é necessário gozar de bons momentos, pois como já dizia Cícero, [e1] como se pode realmente "viver a vida" sem conhecer a felicidade de encontrar num amigo os mesmos sentimentos? (Texto 220, $\left.\S 3^{\circ}\right)$; 
Exemplo 9

É complicado viver sem a felicidade de se encontrar num amigo. Assim como, [e2] não há nada mais doce do que confiar inteiramente em alguém. [e3] A felicidade seria desnecessária se não houvesse com quem o homem compartilhá-la, como o mestre e o discípulo, cujas vitórias e alegrias de um, são também do outro. (Texto $04, \S 2^{\circ}$ );

\section{Exemplo 10}

Não é difícil entender a razão dessa medicalização da vida cotidiana. Cícero já sabia quão difícil é [e4] "suportar adversidades sem um companheiro que as sofresse mais ainda". (Texto $08, \S 4^{\circ}$ );

\section{Exemplo 11}

A amizade representa uma das relações mais puras e belas que existem. Pensadores famosos como Cícero e Sêneca viam a amizade como um bem indispensável à vida. Já dizia Cícero: [e5] "Os que suprimem a amizade da vida aparecem-me privar o mundo do sol". (Texto $\left.20, \S 1^{\circ}\right)$;

\section{Exemplo 12}

Cícero sobre a amizade: [e6] "os deuses imortais nada nos deram de melhor, nem de mais agradável", só falta ao homem poder usufruir melhor desta dádiva dos deuses, apreendendo a equilibrar o trabalho e o lazer. (Texto $105, \S 5^{\circ}$ ).

Por meio desses exemplos, mostramos como os seis enunciados que constituem o excerto de Cícero são candidatos ao estatuto de enunciados citáveis. Esses enunciados não apenas assentam o dizer do escrevente no contexto da prova, como fazem parte de um arquivo interno ao evento. Ademais, essas citações não apenas dizem o ponto de vista de Cícero; elas mostram o que do excerto de Cícero foi interessante citar. Passemos ao excerto de Montaigne:

\section{EXCERTO DE MONTAIGNE}

Aprecio no mais alto grau a resposta daquele jovem soldado, a quem Ciro perguntava quanto queria pelo cavalo com o qual acabara de ganhar uma corrida, e se o trocaria por um reino: 
"Seguramente não, senhor, e, no entanto eu o daria de bom grado se com isso obtivesse a amizade de um homem que eu considerasse digno de ser meu amigo". E estava certo ao dizer se, pois se encontramos facilmente homens aptos a travar conosco relações superficiais, o mesmo não acontece quando procuramos uma intimidade sem reservas. Nesse caso, é preciso que tudo seja límpido e ofereça completa segurança.

Eis alguns exemplos que mostram os gestos de leitura do enunciado acima destacado em negrito:

Exemplo 13

É claro que, como bem afirmou o pensador do século XVI, Montaigne, não é nada fácil conquistar-se uma relação de "intimidade sem reservas". Todavia, desde que se encontre a amizade verdadeira, pode-se descobrir um sentimento, às vezes, superior até ao mais sublime amor de um homem por uma mulher. (Texto $06, \S 3^{\circ}$ );

Exemplo 14

Montaigne, pensador do século XVI, já ressaltava a dificuldade de se encontrar uma amizade íntima e segura em seu texto "Da amizade". Nos tempos atuais, a competitividade no mercado de trabalho e a valorização dos bens materiais agravam o problema, no caso dos adultos. (Texto $30, \S 2^{\circ}$ );

Exemplo 15

Montaigne, em suas reflexões, oferece alguns elementos que nos permitem abordar melhor a questão. Ao apresentar a amizade como um tipo de relacionamento no qual se busca uma intimidade sem reservas, Montaigne põe o foco em um aspecto das relações pessoais que, se foi complexo em seu tempo, seguramente é problemático na sociedade ocidental contemporânea. (Texto 34, $\S 4^{\circ}$ );

Exemplo 16

Existem aqueles que se consideram amigos de verdade e na menor oportunidade traem e desaparecem. Isso ocorre pelo fato de haver muitas pessoas aptas a travar relações superficiais e poucas aptas a travar uma amizade plena como afirmou, corretamente, o pensador Montaigne no século XVI. (Texto $41, \S 3^{\circ}$ ); 


\section{Exemplo 17}

A obtenção de um amigo é uma conquista que pode levar anos para se concretizar. Como ressaltou Montaigne, em "Da Amizade", encontramos facilmente pessoas que queiram manter relações supérfluas e superficiais conosco. (Texto $106, \S 2^{\circ}$ );

Os exemplos acima implicam em um modo "cristalizado" de ler o excerto de Montaigne. Ao centrar a leitura desse excerto no enunciado destacado, o escrevente mostra como seu projeto de dizer é alimentado pela iconografia de sua época. A repetição desse enunciado mostra uma representação cristalizada que o escrevente tem da amizade. Essa cristalização, por sua função ideológica, não reflete simplesmente a incapacidade de senso crítico do escrevente, mas permite a coesão social, dando identidade a um determinado grupo social (cf. BRANDÃO, 2006).

Os dados nos mostram como esses modos de representação do discurso outro são atravessados por leituras cristalizadas (estereotipadas), fazendo circular o imaginário social que inspira e alimenta um determinado grupo e sua época. Partindo, então, do princípio de que falamos com as palavras dos outros para construirmos nossos discursos, pode-se afirmar o seguinte: quando o pré-construído próprio à natureza da atividade de leitura se torna repetitivo, automatizado, uma representação coletiva congelada, cristalizada em um grupo social, temos uma leitura estereotipada. O mesmo pode ser observado nos gestos de leitura de "Canção da América".

\section{EXCERTO DE MILTON NASCIMENTO E FERNANDO BRANT}

Amigo é coisa pra se guardar,

Debaixo de sete chaves,

Dentro do coração...

Assim falava a canção

Que na América ouvi...

Mas quem cantava chorou,

Ao ver seu amigo partir...

Mas quem ficou,

No pensamento voou,

Com seu canto que o outro lembrou. 
Eis os exemplos:

\section{Exemplo 18}

Portanto, Milton Nascimento estava certo ao cantar que "Amigo é coisa pra se guardar, / Debaixo de sete chaves". Afinal, em uma sociedade formada por cidadãos competitivos e inseguros, encontrar alguém disponível a partilhar sentimentos abertamente não é só difícil, como beira o impossível. (Texto $30, \S 4^{\circ}$ );

\section{Exemplo 19}

Como diz a música de Milton Nascimento e Fernando Brant, "amigo é coisa pra se guardar / debaixo de sete chaves" e, ao acharmos alguém com tanto valor, é preciso agradecer. (Texto 142, §2 $2^{\circ}$;

\section{Exemplo 20}

Eu sabia que "amigo é coisa pra se guardar, debaixo de sete chaves, dentro do coração" como fala "Canção da América", mas ainda, o que é ser amigo? (Texto $176, \S 3^{\circ}$ );

Exemplo 21

Por todos esses motivos é adequado ratificar o verso de Canção da América que diz que "amigo é coisa pra se guardar a sete chaves" (Texto 245, $\S 5^{\circ}$ );

Exemplo 22

"Amigo é coisa pra se guardar, debaixo de sete chaves, dentro do coração...", eternizada na voz de Milton Nascimento, a "Canção da América" representa bem esse sentimento que existe "desde que o homem é homem". (Texto $342, \S 1^{\circ}$ ).

Diferentemente dos excertos de Cícero e Montaigne, o enunciado destacado de "Canção da América" circula no imaginário de nossa sociedade com um estatuto de provérbio; como uma fórmula cristalizada sobre a amizade; como um enunciado facilmente memorizável. Assim como os slogans, faz parte da natureza desse enunciado ser repetido em bloco compacto. Esse enunciado é afetado pela doxa e repousa sob um jádito do imaginário social que "enaltece" a amizade. Ademais, esse "enunciado destacado" pode ser interpretado como "enunciado destacado por natureza", uma vez que já faz parte do imaginário social sobre a amizade. 
9 CONCLUSÃO

Neste artigo, por meio da análise do percurso interno de leitura inscrito na produção textual de pré-universitários, buscamos:

(i) Descrever as formas de heterogeneidade mostrada (explícitas e interpretativas) que marcam a constante negociação do sujeito com a heterogeneidade que lhe é constitutiva. Por meio desta descrição, pude observar que determinadas formas aparecem com mais frequência. Essa observação, por sua vez, me leva a crer na hipótese de uma possível relação contratual entre as formas de heterogeneidade mostrada e os gêneros discursivos. Em outras palavras, acredito que o gênero discursivo seja uma das instâncias que regula o modo como o discurso outro será mostrado;

(ii) Mostrar que essa apropriação do texto da coletânea pode ser vista não apenas como uma mera leitura contratual, isto é, a atividade de leitura dos textos da coletânea não é um mero acontecimento que se dá apenas na relação escrevente/corretor; a atividade de leitura não fica limitada ao plano do mostrado. Há nessa atividade de leitura algo que lhe é constitutivo, isto é, a leitura mostrada pelo escrevente é atravessada por pré-construídos que circulam em uma dada sociedade. Quero dizer com isso que a leitura é uma atividade permeada pelo já-experimentado, ou seja, o que legitima o acontecimento da leitura no vestibular não é apenas a sua finalidade (uma relação do tipo "estou lendo para uma banca corretora"), mas, também, a retomada de outros discursos e outros sujeitos com os quais o escrevente lê. Por sua vez, essa leitura com outros discursos e outros sujeitos faz circular enunciados cristalizados (estereotipados) que alimentam uma determinada comunidade discursiva.

\section{REFERÊNCIAS}

AUTHIER-REVUZ, J. Entre a transparência e a opacidade. Um estudo enunciativo do sentido. Porto Alegre: EDIPUCRS, 2004.

. Palavras incertas: as não-coincidências do dizer. Campinas: Editora da Unicamp, 1998. 
. Heterogeneidade(s) enunciativa(s). Cadernos de Estudos Linguísticos, Campinas, v. 19, p. 25-42, 1990.

BAKHTIN, M. Estética da criação verbal. Trad. do russo de Paulo Bezerra. São Paulo: Martins Fontes, 2003.

BOCH, F.; GROSSMANN, F. Referir-se ao discurso do outro: alguns elementos de comparação entre especialistas e principiantes. In: Scripta, Belo Horizonte, v. 6, n.11, p. 97-108, 2002.

RINCK, F.; BOCH, F.; GROSSMANN, F. Quelques lieux de variation du positionnement énonciatif dans l'article de recherche. In: Filologia e Linguística Portuguesa, v. 8, p. 451-464, 2006.

BOURDIEU, P. A economia das trocas linguísticas. 2. ed. São Paulo: Edusp, 1998.

BRANDÃO, H. H. N. A escrita de estudantes pré-universitários: representação e estereotipia. In: Filologia e Linguística Portuguesa, v. 8, p. 239-250, 2006.

CORRÊA, M. L. G. Letramento e heterogeneidade da escrita no ensino de português. In: SIGNORINI, Inês (Org.). Investigando a relação oral/escrito e as teorias de letramento. São Paulo: Mercado de Letras, 2001. p. 135-166.

Fontes, 2004.

. O modo heterogêneo de constituição da escrita. São Paulo: Martins

. A produção escrita de formandos em Letras: a experiência do provão. In:

OLIVEIRA, M. (Org.) Língua portuguesa em São Paulo: 450 anos. São Paulo: Humanitas, 2006. p. 141-165.

DUARTE, C. Uma análise de procedimentos de leitura baseada no paradigma indiciário. 1998. 167f. Dissertação (Mestrado em Linguística)-Universidade Estadual de Campinas, Campinas (SP), 1998.

DUCROT, O. O dizer e o dito. Trad. Eduardo Guimarães [et al.]. Campinas, SP: Pontes, 1987.

MAINGUENEAU, D. Gênese dos discursos. Trad. Sírio Possenti. Curitiba: Criar edições, 2005.

. Cenas da enunciação. Organização Sírio Possenti e Maria Cecília Pérez de Souza-e-Silva. Curitiba: Criar Edições, 2006.

. A aforização proverbial e o feminino. In: MOTTA, A. R.; SALGADO, L.

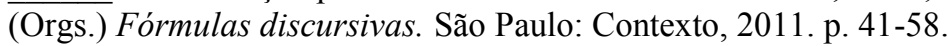

PÊCHEUX, M. O discurso: Estrutura ou acontecimento. 3. ed. Trad. Eni Puccinelli Orlandi. Campinas: Pontes, 2002.

TFOUNI, L. V. Letramento e alfabetização. São Paulo: Cortez, 2010. 
ANEXO2

REDAÇÃO

Em primeiro lugar (...), pode-se realmente "viver a vida" sem conhecer a felicidade de encontrar num amigo os mesmos sentimentos? Que haverá de mais doce que poder falar a alguém como falarias a ti mesmo? De que nos valeria a felicidade se não tivéssemos quem com ela se alegrasse tanto quanto nós próprios? Bem difícil te seria suportar adversidades sem um companheiro que as sofresse mais ainda.

Os que suprimem a amizade da vida parecem-me privar o mundo do sol: os deuses imortais nada nos deram de melhor, nem de mais agradável.

Cicero, Da amizade.

Aprecio no mais alto grau a resposta daquele jovem soldado, a quem Ciro perguntava quanto queria pelo cavalo com o qual acabara de ganhar uma corrida, e se o trocaria por um reino: "Seguramente não, senhor, e no entanto eu o daria de bom grado se com isso obtivesse a amizade de um homem que eu considerasse digno de ser meu amigo". E estava certo ao dizer se, pois se encontramos facilmente homens aptos a travar conosco relações superficiais, o mesmo não acontece quando procuramos uma intimidade sem reservas. Nesse caso, é preciso que tudo seja límpido e ofereça completa segurança.

Montaigne, "Da amizade" (adaptado).

Amigo é coisa pra se guardar,

Debaixo de sete chaves,

Dentro do coração...

Assim falava a canção

Que na América ouvi...

Mas quem cantava chorou,

Ao ver seu amigo partir...

Mas quem ficou,

No pensamento voou,

Com seu canto que o outro lembrou.

(..)

Fernando Brant / Milton Nascimento,

"Canção da América".
(..)

E sei que a poesia está para a prosa

Assim como o amor está para a amizade.

E quem há de negar que esta lhe é superior? (..)

Caetano Veloso, "Língua".

Considere os textos e a instrução abaixo:

INSTRUÇÃO: A amizade tem sido objeto de reflexões e elogios de pensadores e artistas de todas as épocas. Os trechos sobre esse tema, aqui reproduzidos, pertencem a um pensador da Antigüidade Clássica (Cicero), a um pensador do século XVI (Montaigne) e a compositores da música popular brasileira contemporânea. Você considera adequadas as idéias neles expressas? Elas são atuais, isto é, você julga que elas têm validade no mundo de hoje? O que sua própria experiência the diz sobre esse assunto? Tendo em conta tais questões, além de outras que você julgue pertinentes, redija uma DISSERTAÇÃO EM PROSA, argumentando de modo a expor seu ponto de vista sobre $o$ assunto.

2 Prova disponível em: <http://www.fuvest.br/vest2007/provas/2fase/por/por06.stm>. Acesso em: 31 mar. 2008.

Linguagem em (Dis)curso, Tubarão, SC, v. 13, n. 3, p. 639-665, set./dez. 2013. 


\section{Recebido em 04/06/13. Aprovado em 01/12/13.}

Title: A discursive-enunciative analysis of "internal reading patterns" staged in the textual production of pre-university students Author: Luiz André Neves de Brito

Abstract: The article aims to present partial results of a discursiveenunciative analysis of a representative corpus of FUVEST/2007 essays produced by candidates selected in the first call of this examination. Assuming the Discourse Analysis approach related to the enunciation perspective, this paper focuses on the immediate conditions of production to analyze (i) the points of shown heterogeneity from the relationship between selection texts of exam/texts produced by candidates; and (ii) the "crystallized" event of this internal pattern of reading. Through this analysis, I argue that (i) the discursive genre is one of the instances that regulates how the other's discourse will be shown; and (ii) the reading shown by candidates, in the context of this examination, is crossed by common knowledge experienced in a given society.

Keywords: Discourse analysis. Written work from pre-university students. Internal reading patterns.

Título: Un análisis enunciativo-discursivo de los "recorridos internos de lectura" escenificados en la producción textual de preuniversitarios

Autor: Luiz André Neves de Brito

Resumen: El artículo tiene como objetivo presentar resultados parciales de un análisis discursivo-enunciativo de un corpus representativo de redacciones de la FUVEST/2007, producidas por candidatos seleccionados en primera llamada del examen de ingreso a la universidad. Asumiendo la vertiente del Análisis del Discurso ligada a la perspectiva da enunciación, focalizo las condiciones inmediatas de producción para analizar (i) los puntos de heterogeneidad mostrada a partir de la relación coletánea/textos producidos; y (ii) el hecho "cristalizado" de ese recorrido interno de lectura. Por medio de ese análisis, defiendo que (i) el género discursivo sea una de las instancias que regula el modo como el discurso será mostrado; y (ii) la lectura mostrada por el escribiente, en el contexto de examen de ingreso a la universidad, es franqueada por prefabricados que circulan en una dada sociedad.

Palabras-clave: Análisis del discurso. Escritura de preuniversitarios. Recorridos internos de lectura. 